\title{
EFFECTS OF TREE DESTRUCTION AND DEBRIS DAM FORMATION AT THE GRAVEL-BED BARS IN KUMAGAYA IN THE ARAKAWA RIVER ON THE MAXIMUM WATER DEPTH AND FLOOD HYDROGRAPH DURING THE FLOOD EVENT CAUSED BY TYPHOON HAGIBIS
}

\author{
Norio TANAKA ${ }^{1}$, Yoshiya IGARASHI ${ }^{2}$ and Hiroshi SUENAGA ${ }^{3}$ \\ ${ }^{1}$ Member of JSCE, Professor, Graduate School of Science and Engineering, Saitama University \\ (255 Shimo-okubo, Sakura-ku, Saitama 338-8570, Japan) \\ E-mail: tanaka01@mail.saitama-u.ac.jp (Corresponding Author) \\ ${ }^{2}$ Member of JSCE, Assist. Professor, Graduate School of Science and Engineering, Saitama University \\ (255 Shimo-okubo, Sakura-ku, Saitama 338-8570, Japan) \\ E-mail: yigarashi@mail.saitama-u.ac.jp \\ ${ }^{3}$ Member of JSCE, Graduate School of Science and Engineering, Saitama University \\ (255 Shimo-okubo, Sakura-ku, Saitama 338-8570, Japan)
}

\begin{abstract}
During the flood event caused by Typhoon Hagibis, a large number of trees on the forested gravel bars were destructed in Kumagaya, on the alluvial fan in the Arakawa River. Parts of the trees were trapped in the downstream bars and formed debris dams. The change in the resistance by a debris dam could affect not only the formation of repelling current, but also the flood propagation downstream. A two-dimensional flood simulation model of the destruction and trapped driftwoods was applied to the site, to clarify the changes in flow pattern due to the destructive flood. The maximum velocity was decreased on the gravel bar where debris dams were formed although the velocity was increased by the destruction in the low channel. The tree destruction situation itself was mitigated in the sheltered area of the forest by the debris dam formation. From the point of the maximum water depth at the embankment, the trapping effect was low in the case of Arakawa River, which has a wide cross-section, but it also reduced the peak discharge by around $10 \mathrm{~m}^{3} / \mathrm{s}$.
\end{abstract}

Key Words : gravel bar, vegetation resistance, washout, trapping, flood retention

\section{INTRODUCTION}

The recent 2019 Typhoon Hagibis recorded very heavy rain in East Japan and overflowing from the levee, and levee breaches occurred in many rivers. The number of damaged rivers and breached locations were 2 and 14, respectively, for the rivers managed by the Ministry of Land, Infrastructure, Transport and Tourism, Japan (MLIT); and 67 and 128 for those managed by prefectures ${ }^{1)}$.

Checking the 2019 flood situation in the Arakawa River system, Kanto District in Japan, the discharge at Sugama $\left(4100 \mathrm{~m}^{3} / \mathrm{s}\right)$ exceeded the design level flood discharge $\left(3300 \mathrm{~m}^{3} / \mathrm{s}\right)$ in the Irumagawa River, branch of the Arakawa River. In the Irumagawa Basin, overflow and levee breaches occurred in five locations. In the watershed, urgent river improvement plan was discussed and has been ongoing after the flood event. The excavation of the river cross-section and the riparian forest management are among the countermeasures in the project.

On the other hand, overflow from the levee did not occur in the main Arakawa River, but the water level became high and it continued for a long time. To decrease the water level, a flood retention pond (which is being designed) should be constructed in the future. In addition, the effect of the forestation upstream of the main Arakawa River should be clarified from the point of view of how it changes the flood hydrograph to downstream. Especially, the forestation is now ongoing in the upstream Kumagaya alluvial fan. The trees are sometimes washed out at a 
large flood event and driftwoods are trapped in the gravel bars. It can greatly change the resistance at flood events.

In history, levee breaching frequently occurred during large flood events in the Kumagaya alluvial $\mathrm{fan}^{3), 4}$. At the forest on the gravel bar in Kumagaya, large number of tree breakage and washout occurred in $2006^{5}$. Although no levee breach or overflow occurred, it is important to know the types of destructions that occurred at the 2019 event, with discharge larger than that in the 2006 event, to determine the future risk in the area and also downstream area by changing the flood hydrograph.

To understand the change in resistance during the flood event, it is very important to classify the types of tree breakage and each threshold value for breaking or washing out of trees ${ }^{5), 7), 8), 9), 10)}$. Tanaka et al. ${ }^{5}$ conducted a post-flood survey of the September 2007 event in the Tamagawa River and the Arakawa River. The study classified the types of tree damage as 'tree trunk breakage, bending or overturning,' which is related to the moment acting by the drag force, and 'washout,' which is related to the bed shear stress. Considering these phenomena, two non-dimensional parameters were proposed and the method to estimate forestation dynamics on the gravel bar has been proposed. The method can be applied for the estimation of the resistance change during the flood event.

In addition, a large number of driftwood was trapped at the 2019 event. It can also greatly change the resistance in the vegetated area. It is very important to know the situation of vegetation change in the river for discussing the management of forest not only from the river capacity at the location, but also from the point of view of the upstream-downstream balance of flood countermeasures.

Therefore, this study conducted a post-flood survey in the alluvial fan area in the Arakawa River, paying special attention to knowing the vegetation destruction and trapping situation. By including the destruction and trapping processes into the numerical model, the change in flood hydrograph is also discussed.

\section{POST-FLOOD SURVEY ON THE VEGE- TATION WASHOUT AND DRIFT- WOOD TRAPPING SITUATION}

Post-flood surveys were mainly conducted on two gravel bars, KU2 and AR2, shown in Fig.1. To increase the data of trapped debris characteristics, HO was added to the survey site. The details of the survey locations of KU2, AR2, and $\mathrm{HO}$ are shown as open plots in Fig.1(c), (d), and (e), respectively.

The bed gradient in HO, KU1, and AR2 are almost
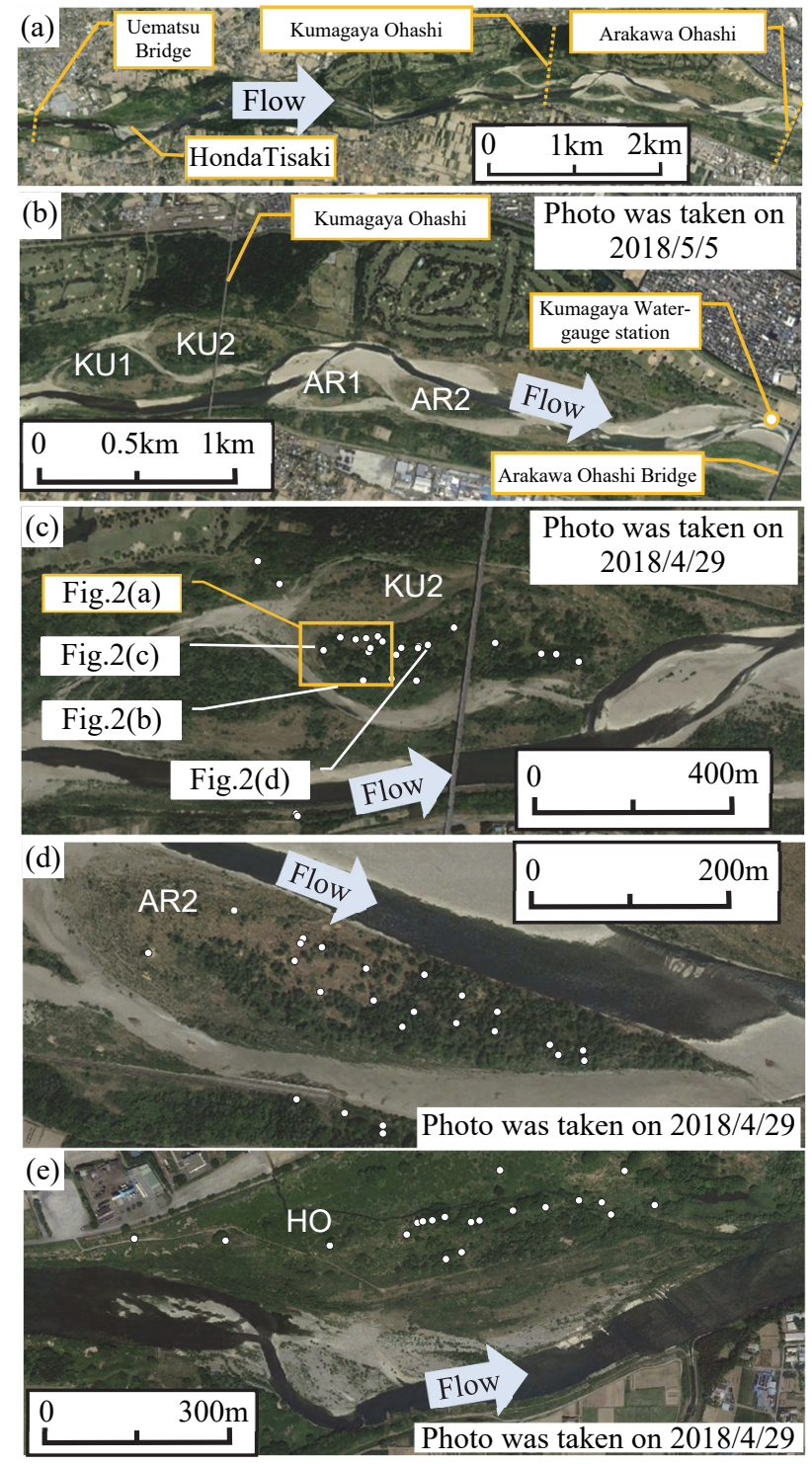

Fig.1 Gravel bars investigated after the 2019 Typhoon Hagibis. (a): Whole area (Arakawa River, 77.6k-80.4k), (b): Location of four gravel bars (AR1, AR2, KU1, KU2), (c), (d): Plots where debris characteristics was obtained in KU2, AR2, respectively, (e): Honda Tisaki shown in (a), Modified from the Google earth. Upward is the north direction.

the same, $1 / 375$, and $d_{50}$ (diameters at which $50 \%$ of the volume are passed through a sieve) in HO, KU1, and AR2, are $6.9,6.5$, and $3.3 \mathrm{~cm}$, respectively ${ }^{11}$. Previous research ${ }^{5}$ was conducted in KU1 and AR2, however, the survey on the same site was a little difficult this time because of the development of the channel in between KU1 and KU2. In addition, debris trapping largely occurred in KU2 (Fig.2), so KU2 was selected instead of KU1.

In each gravel bar, 20 sample trees that trapped debris in front of the tree trunk were selected and the scale of the trapped debris clump (hereafter TDC) was measured from cross-stream and upstream direction. The location (longitude, gratitude, elevation) was also recorded using RTK-GNSS (R-10:Trimble Inc.). The washout situation was surveyed using UAV (Mavic Pro: DJI) while the software DJI GS 

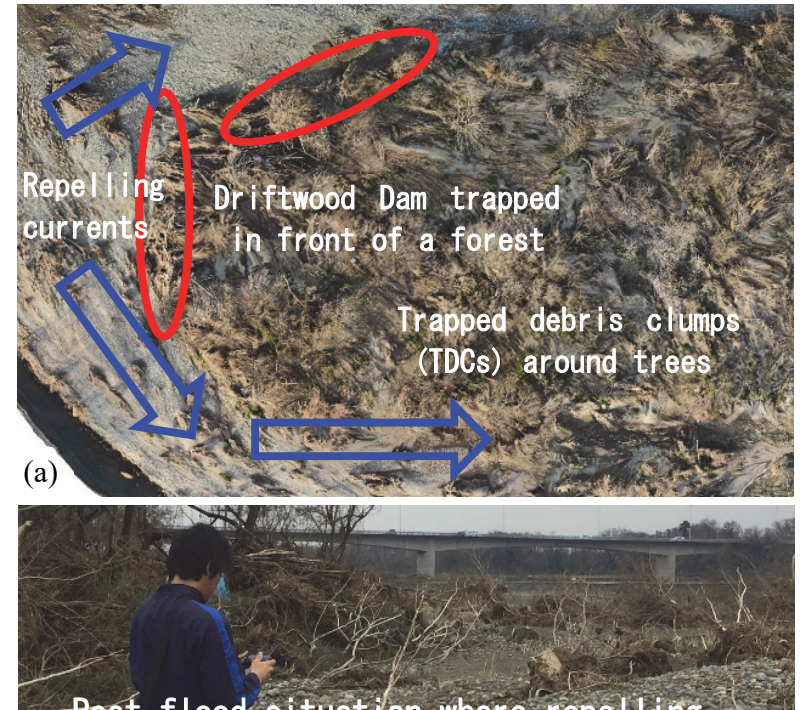

Post flood situation where repelling current flows by around debris dam (tree

(b) overturning and Hassiout)
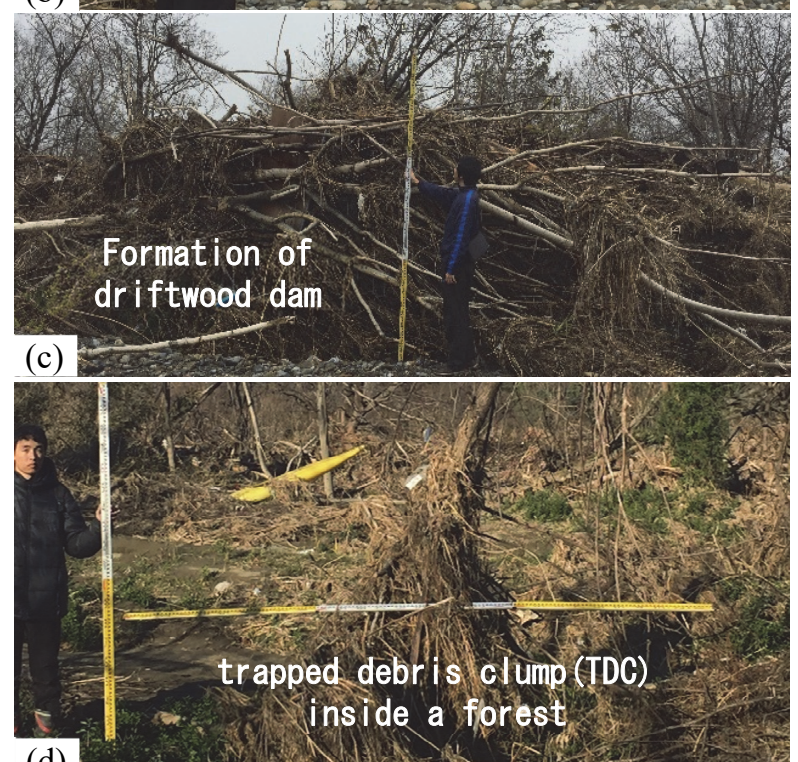

Fig.2 Trapped situation of debris around the forest in KU2 (Location is shown in Fig.1).

Pro was used to take aerial views automatically. The aerial photos were taken from $100 \mathrm{~m}$ in height and 3$4(\mathrm{~cm} / \mathrm{pix})$ digital images were obtained. From a large number of aerial photographs, 'ortho images,' which were geometrically corrected to make the scale uniform, were obtained from the software of Structure from Motion (PhotoScan Professional: Agisoft). Using the ortho images, the width of the scoured region around the trees, which largely trapped the debris, was measured and validated with some of the actually measured values in situ. The ortho images in KU2 and AR2 are shown in Figs.3(a) and (b), respectively.

For the scale characteristics of TDC, tree diameters at breast height $(1.2 \mathrm{~m})$, maximum flood mark heights, and the widths of the TDC in front of trees were investigated. When the height of TDC was larger than $1.2 \mathrm{~m}$ and the tree trunk could not be seen,
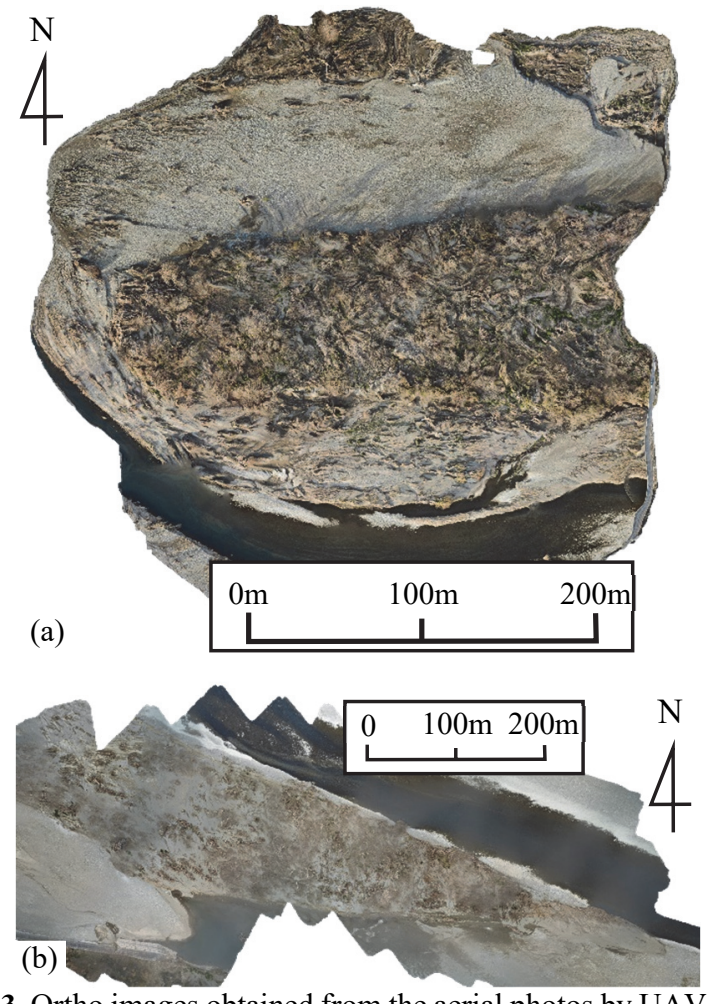

Fig.3 Ortho images obtained from the aerial photos by UAV, (a) KU2 (Upstream side of the Kumagaya Ohashi Bridge, (b) AR2.

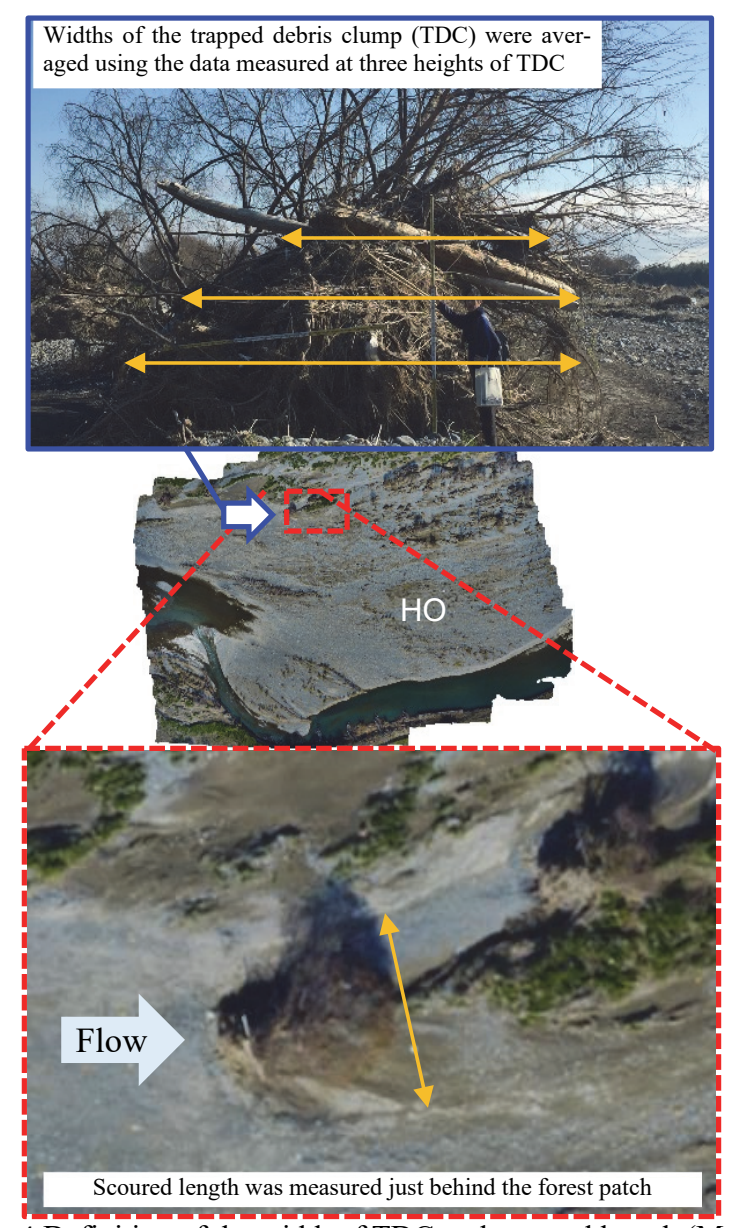

Fig.4 Definition of the width of TDC and scoured length (Modified from the photos taken at field survey and ortho images at $\mathrm{HO}$ ). 
the trunk height was measured at the minimum possible height at which trunk diameter could be measured. When the widths of TDC varied in height, the width was averaged from the values at three locations of the TDC (Fig.4). In addition, the material of TDC was classified into three groups, G, GR, and GRT, where $\mathrm{G}, \mathrm{R}$, and $\mathrm{T}$ referred to grasses, roots or small branches, and trees, respectively. The classification paid attention to the resistance of the organization. The resistance of $\mathrm{G}$ was assumed to be relatively small because it consisted of soft material. GR contained hard material, roots and branches, other than $\mathrm{G}$, the resistance was assumed to be larger than $\mathrm{G}$. GRT was assumed to be the maximum in the three classifications because it contained trees. In addition, the trapped width had a possibility to be larger than that of G or GR. The plane distribution of flood levels were obtained from the flood water mark captured by the photos, and land elevation data were taken from RTK-GNSS, or Laser Profile (LP) data.

Figure 5 shows the relationship between tree trunk diameter and the width of TDC. The width became larger with the increase in diameter till around $0.2 \mathrm{~m}$; however, the increment became very small over the diameter. The variation in the width with the TDC material is large and increases with the order of $G$, GR, and GRT. Especially, GRT which includes tree debris is large, but the difference between G and GR is small. The difference in gravel bars could not be seen. From the data in Fig.5, the relationship is functionalized and used in numerical simulation for calculation of additional resistance after trapping debris.

\section{FLOOD SIMULATION METHOD IN- CLUDING VEGETATION WASHOUT AND TRAPPING DRIFTWOOD}

\section{(1) Fundamental equations}

This study adopted a two-dimensional non-linear depth-averaged flow model in the Arakawa region (continuity equation: Eq.(1), momentum equations: Eqs.(2)-(5)), the same with Tanaka et al. (2019).

$$
\begin{gathered}
\theta \frac{\partial \eta}{\partial t}+\frac{\partial Q_{x}}{\partial x}+\frac{\partial Q_{y}}{\partial y}=0 \\
\frac{\partial Q_{x}}{\partial t}+\frac{\partial}{\partial x}\left(\frac{Q_{x}{ }^{2}}{\theta h}\right)+\frac{\partial}{\partial y}\left(\frac{Q_{x} Q_{y}}{\theta h}\right)+\theta \operatorname{gh} \frac{\partial \eta}{\partial x} \\
+\theta \frac{\tau_{b x}}{\rho}+\theta \frac{f_{x}}{\rho}=0 \\
\frac{\partial Q_{y}}{\partial t}+\frac{\partial}{\partial x}\left(\frac{Q_{x} Q_{y}}{\theta h}\right)+\frac{\partial}{\partial y}\left(\frac{Q_{y}{ }^{2}}{\theta h}\right)+\theta \operatorname{gh} \frac{\partial \eta}{\partial y} \\
+\theta \frac{\tau_{b y}}{\rho}+\theta \frac{f_{y}}{\rho}=0
\end{gathered}
$$

where $x$ and $y$ are the horizontal coordinates in a Car-

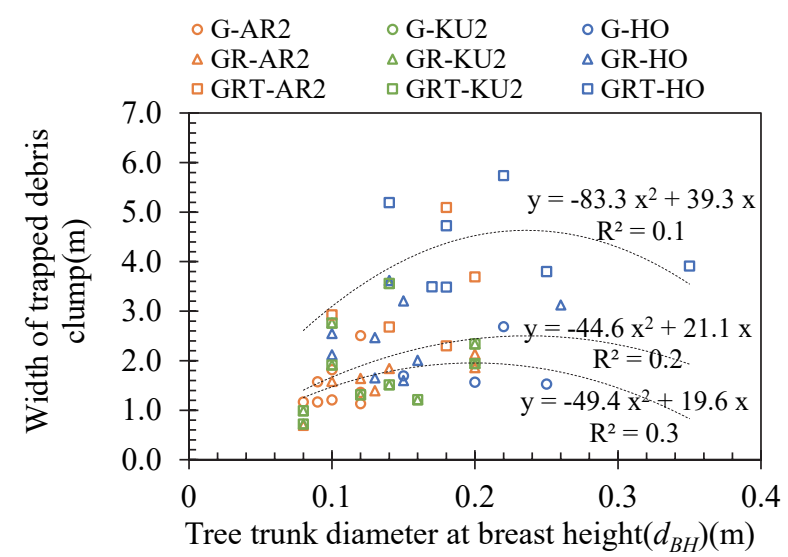

Fig.5 Relationship between $d_{B H}$ and width of trapped debris clump.

tesian coordinate system; subscript $x$ or $y$ means the direction of the respective value; $Q$ is the unit discharge; $\tau_{b}$ is the bed shear stress; $f$ is the resistance by vegetation in unit area; $t$ is the time; $h$ is the total water depth; $\eta$ is the water surface elevation; $g$ is the gravitational acceleration; and $\rho$ is the density of water.

The bed shear stress and drag force in $x, y$ directions can be defined as:

$$
\begin{aligned}
\left(\tau_{b x}, \tau_{b x}\right)= & \left(Q_{x}, Q_{y}\right) \times \frac{\rho \mathrm{g} n^{2}}{h^{7 / 3}} \sqrt{Q_{x}{ }^{2}+Q_{y}{ }^{2}} \\
\left(f_{x}, f_{y}\right)=(u, v) & \times \frac{1}{2} m \rho C_{d-r e f} d_{B H} \sqrt{u^{2}+v^{2}} \\
& \times \int_{0}^{h} \frac{d(z)}{d_{B H}} \frac{C_{d}(z)}{C_{d-r e f}} d z \\
\tau & =\sqrt{\tau_{b x}{ }^{2}+\tau_{b y}{ }^{2}}
\end{aligned}
$$

where $m$ is the number of trees in a unit area (trees $\left./ \mathrm{m}^{2}\right), C_{d}(z)$ is the drag coefficient at height $z$, $C_{d-r e f}$ is the reference drag coefficient of trunk ( $=1$ in this study), $d_{B H}$ is the tree trunk diameter at breast height $(=1.2 \mathrm{~m})$, and $n$ is the Manning roughness coefficient.

Land elevation data of Laser Profiler ( $5 \mathrm{~m}$ grid) by MLIT was converted to $50 \mathrm{~m}$ (coarse grid area) and $10 \mathrm{~m}$ (fine grid area). As to the river grid, riverbed elevation was lowered to the average elevation height using cross-sectional profile data. Rivers smaller than the grid size were modeled using the porosity. For example, $10 \mathrm{~m}$ width river in a $50 \mathrm{~m}$-size grid can be modeled using the porosity as 0.2 and the elevation was set at the averaged river bed elevation. Manning roughness coefficient for floodplain was set as a function of landuse ${ }^{6}$. The embankment was modeled as a wall in between the grid and overflow discharge from embankment was calculated using a method in the previous study ${ }^{6}$.

\section{(2) Modeling the resistance by vegetation}

Tree characteristics were set as in Table $\mathbf{1}$ based 
Table 1 Tree characteristics modelled in the simulation.

\begin{tabular}{|c|c|c|c|c|}
\hline & High trees & Low trees & Bamboo & Bamboo grass \\
\hline Tree height $(\mathrm{m})$ & 9 & 3 & 9 & 3 \\
\hline Crown height $(\mathrm{m})$ & 3 & 1.5 & - & - \\
\hline Crown width $(\mathrm{m})$ & 7.5 & 2.8 & - & - \\
\hline $\begin{array}{c}\text { Trunk diameter at breast } \\
\text { height (m) }\end{array}$ & 0.2 & 0.1 & 0.038 & 0.015 \\
\hline Tree density (trees $\left./ \mathrm{m}^{2}\right)$ & 0.03 & 0.03 & 3.43 & 25 \\
\hline Tree-crown's coefficient, $\beta$ & 1.25 & 1.25 & 1 & 1 \\
\hline
\end{tabular}

on the field survey and referring to the 'National Census on River Environments' by MLIT. High trees and low trees were classified at a threshold value of $4 \mathrm{~m}$. This study set the tree height of high and low trees as $9 \mathrm{~m}$ and $3 \mathrm{~m}$, respectively. Tree densities were set using the aerial photos and counted the number of trees in $10 \mathrm{~m}$-square area. The tree density around Kumagaya Ohashi (KU2) and Arakawa Ohashi (AR2) were 0.01-0.05 and 0.01-0.04 trees $/ \mathrm{m}^{2}$, respectively. The characteristics of bamboo trees and bamboo grasses, height, density, and trunk diameter at breast height, were set based on the field survey.

In river floodplain, Manning roughness coefficient in the floodplain in fine grid area in Fig.6(a) were set around $0.035-0.05$ considering the gravel size and vegetation. In addition, large perennial grasses habitat in or around the low channel, Miscanthus sacchariflorus, Phragmites japonica, and Eragrostis curvula, were set at 0.05 and other small grasses habitat were set at $0.035^{6}$. Using the maximum value of $\tau$ in Eq.(6), non-dimensional shear stress of $d_{50}$ and $d_{90}$ (diameters at which $90 \%$ of the volume are passed through the sieve) were calculated by Eq.(7). The threshold value of the movement of $d_{90}$ gravel $\left(\tau_{*_{\mathrm{c}} 90}\right)$ was calculated from Eq. (8) using $\tau_{* c 50}$, the threshold value for $d_{50}$, as 0.06 .

$$
\begin{aligned}
& \tau_{* i}=\frac{\tau_{\max }}{S \rho g d_{i}} \\
& \frac{\tau_{* \mathrm{c} 90}}{\tau_{* \mathrm{c} 50}}=\left[\frac{\log _{10} 19}{\log _{10} 19\left(d_{90} / d_{50}\right)}\right]^{2}
\end{aligned}
$$

where, $d_{i}$ is the gravel size in KU or $\mathrm{AR}\left(d_{50}(\mathrm{~m})\right.$ : $\left.\mathrm{KU}=0.07, \mathrm{AR}=0.05, d_{90}(\mathrm{~m}): \mathrm{KU}=0.11, \mathrm{AR}=0.10\right)^{6}$, and $S$ is the specific weight of gravel in water (1.65).

\section{(3) Washout conditions of trees and large grasses}

For judging the breaking and washout condition of trees in running water, Tanaka et al. ${ }^{5)}$ proposed to use two indices: Breaking and Overturning Index (BOI) and Wash-Out Index (WOI).

BOI uses the moment acting on trees and can evaluate whether a tree overturns or the tree trunks are broken by comparing the threshold values. BOI is defined as $d_{B H_{-} \max } / d_{B H}$, where, $d_{B H}$ is the diameter at breast height, $d_{B H}{ }_{-\max }$ is the maximum diameter of $d_{B H}$ at the flood condition. Tanaka and Yagisawa ${ }^{14)}$ pointed out that the breaking mode is changed from overturning to trunk breakage because the overturn-

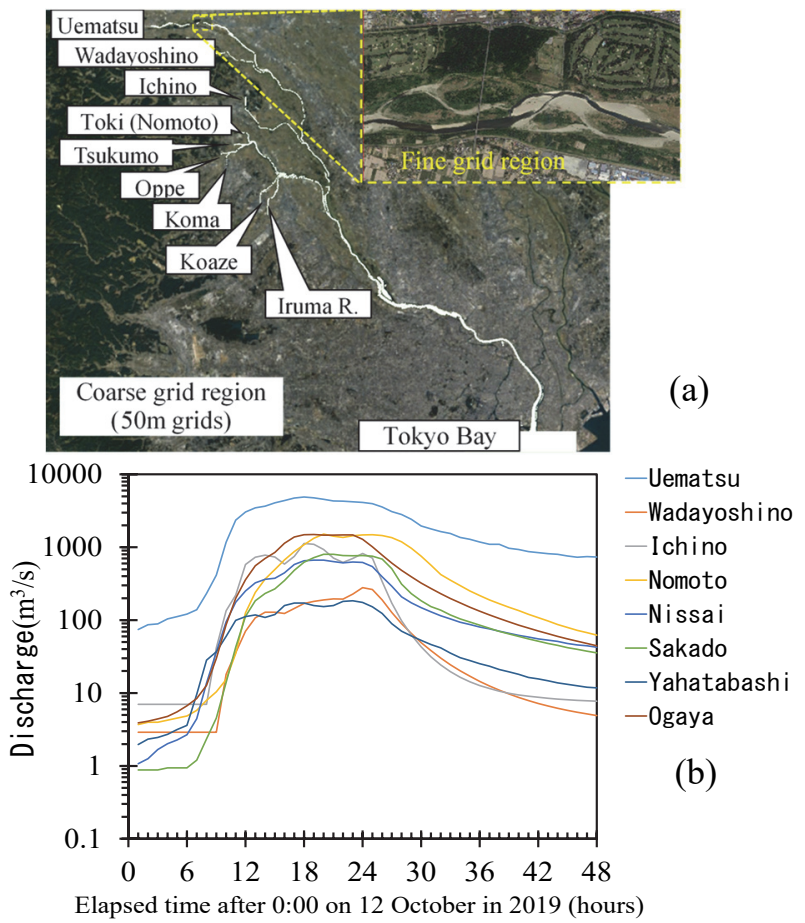

Fig.6 Schematic of the flood model, (a) model structure (locations of boundary condition, simulated area), (b) discharge hydrograph at boundary conditions (a) is modified from the Google Earth. Upward is the north direction.
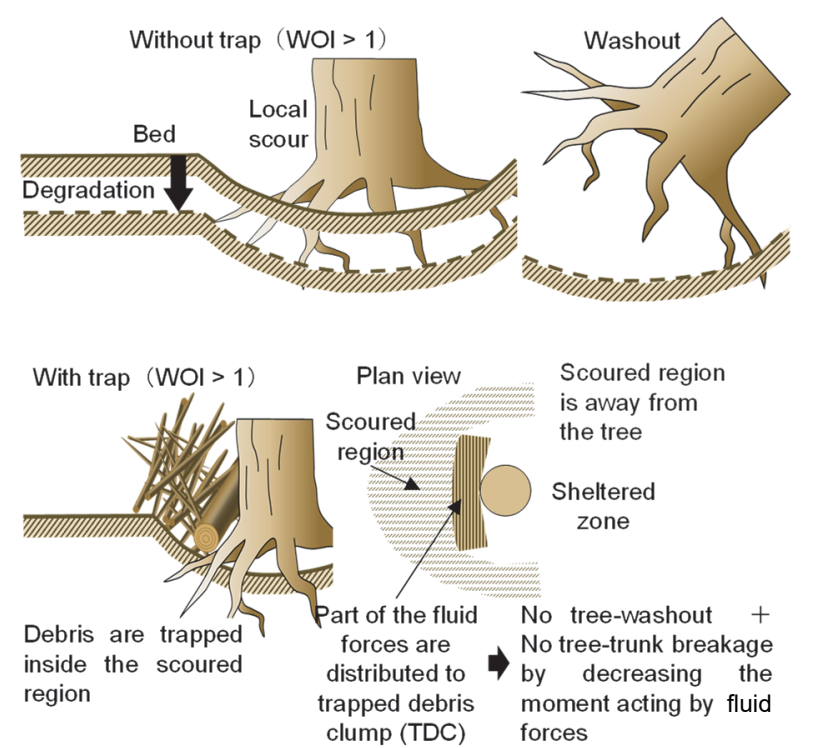

Fig.7 Schematic of the effect of trapping driftwood on local scour and washout condition.

ing is related to $d_{B H^{2}}$ and trunk breakage is a function of $d_{B H^{3}}$. Using the information in the study ${ }^{14)}$ and comparing the critical values of the two destruction modes, the change in resistance at large flood event like this study is modeled.

WOI can judge whether a tree is washed out or not by comparing the bed shear stress with a critical value. WOI is defined as $\tau * 90 / \tau *_{c} 90$, which expresses the ratio of the shear stress acting on $d_{90}$ and the critical value. Similar methods using the critical shear stress were also proposed by Tsujimoto et al. ${ }^{15)}$ and Egger et al. ${ }^{16)}$ 
For judging the washout of a tree, the critical value of WOI was set as 1 using the data in Tanaka et al. ${ }^{5)}$. When a tree trapped debris in the scoured region by horseshoe vortices around a tree trunk, the scoured region just around a tree trunk was observed to decrease, although the scour slightly occurred around the TDC (Fig.7). Then the tree washout itself can be decreased and the WOI judgment for washing out trees was not used further. For large perennial grasses, referring to Yagisawa and Tanaka ${ }^{15)}$, the critical values of Miscanthus sacchariflorus, Phragmites japonica and Eragrostis curvula, were set as 2.0, 2.0, and 1.55 respectively. When the perennial grasses were judged to be washed out, the Manning roughness coefficient was changed to 0.035 , the same as the value in the low channel.

\section{(4) Change of drag coefficient after trapping drift- wood}

The trapping effect of floating debris (including driftwood) is modeled by changing the drag coefficient and projected area of TDC. Considering the material type of the TDC, the horseshoe-shape or cylindrical-shape type, the $C_{d}$ of G and GR was set as 1 . The $C_{d}$ of GRT was set as 1.5 because the shape was like a vertical plate. The width of the TDC was set using the relationship between $d_{B H}$ and the width in Fig.5.

In the field survey, GRT type was mainly observed around the fringe region of forest on gravel bars, and $\mathrm{G}$ or GR was observed inside the forest. The situation was also set in the simulation. Figure 8 shows the initial location of the fringe area and the inside of forest for classifying the trapping type. The fringe was changed in time because of the washout of trees. The width of TDC were functionalized by a trunk diameter at breast height (Table 1) and the field survey data in Fig.5, and set in the numerical model. The trapping procedure was applied on the four gravel bars. After trapping procedure started, washout of trees were not considered as described. The trapping procedure started after 37000 seconds when the target gravel bars were inundated.

\section{(5) Model structure and boundary conditions}

This study adopted a two-dimensional non-linear depth-averaged flow model in the Arakawa region. The continuity equation itself was modified in the previous studies ${ }^{6), 18)}$. For applying the model in this study, the vegetation drag term was first added. Second, the boundary condition was changed. The timeseries data during Typhoon Hagibis event were applied at the boundary using measured water level and estimated discharge calculated from water-level and discharge relationship before the flood event. Third, as levee-breaching occurred in the Tokigawa River,

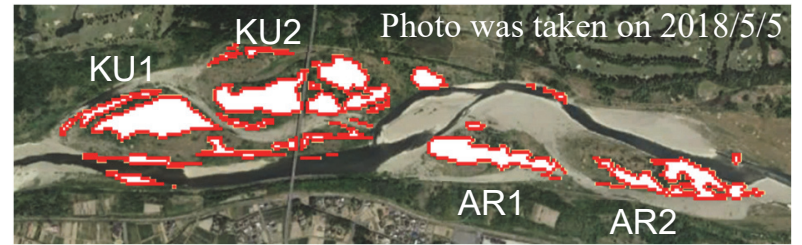

Fig.8 Initial location of two type trapping area. White and red are inside and fringe area, respectively. Modified from the Google Earth. Upper side of this figure is the north.

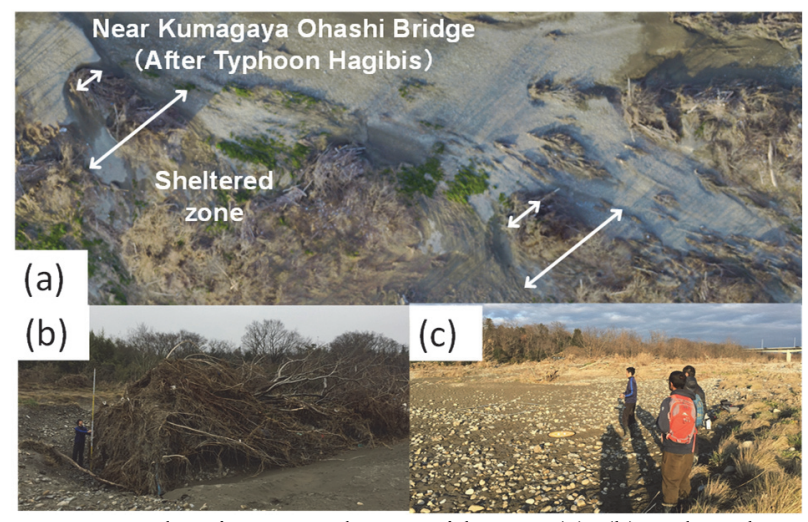

Fig.9 Scoured region around trees with TDC (a), (b) and washout situation of grasses (c).

the location of the boundary condition was changed. Fourth, two-way nesting model ${ }^{19)}$ was applied of which the calculated data in coarse grid $(50 \mathrm{~m})$ and fine grid $(10 \mathrm{~m})$ were linked in each time step. The complementary data were calculated using the storage function model of the Arakawa River ${ }^{20)}$ and water level-discharge curve, where the time-series data were missing because of the destructive large flood event. The schematic of the model and boundary conditions are shown in Fig.6. For the initial water depth and discharge at each grid, 96 hours of approach calculation using the data at time zero in each boundary condition was performed. After setting the initial condition, the time-series data in Fig.6 were applied.

\section{RESULTS AND DISCUSSION}

\section{(1) Scoured characteristics around trapped debris clumps (TDCs)}

Figure 9 shows the photos of the tree damage condition and the local scour around TDC. When the driftwood dams like those in Fig.2(a), (c), or TDC formed in front of a tree, or root clump appeared in water because of overturning, a horseshoe scoured region was formed corresponding to the scale of the driftwood dam, TDC or root clump. The scoured region was also formed without the trapping; however, the scale was greatly changed from the order of tree trunk diameter to the order of TDC or forest. By the trapping, a large shelter zone of low velocity was generated and the tree in the zone was protected (Fig.9(a)). 
Figure 10 shows the relationship between the diameter at breast height $\left(d_{B H}\right)$ and the non-dimensionalized scour width (scour width/ $d_{B H}$ ). As the number of samples of $\mathrm{G}$ type in $\mathrm{HO}$ and $\mathrm{KU} 2$ gravel bars were low, the plots for G are shown only in AR2 (average $(\mu): 28.2$, standard deviation $(\sigma)$ : 10.8). The values for GR and GRT are not much different in HO and KU2 $(\mu=35-45)$ and slightly smaller in AR2 $(\mu=27-30)$. Considering the data in Figs.5 and 10, the trapping width and scoured region are less related to the diameter and more related to the debris production and the material characteristics.

Backwater-rise due to the trapping of debris in front of bamboo forest near the breaching location of the Tokigawa River was pointed out in the previous study ${ }^{19}$. Although the scoured region is not clearly observed in the Tokigawa's case due to the cohesive material of the floodplain, local backwater rise and local acceleration of flowing water around the forest could affect the safety of the levee. Therefore, even in the patch-type forest, knowledge on the safe region between the forest and the levee is needed even when the trapping phenomenon occurs.

\section{(2) Model validation using the flood water mark and the simulated water level}

Figure 11(a) compares the observed flood water mark height and the simulated water level at the righthand side (r.h.s.) of the river. As an almost similar trend is reproduced, only the data at r.h.s. are shown. Although at around $65-70 \mathrm{k}$, the difference is a little large $(-25 \mathrm{~cm}$ to $+53 \mathrm{~cm})$, the differences in the target sites (two gravel bars: KU2 and AR2), which are located in between 77.6-80.4k, are small. Figure 11(b) shows the comparison of the maximum height of the TDC with simulated maximum water depth. The simulated values are $0-1 \mathrm{~m}$ larger than the observed TDC heights. From the debris trap experiment by Pasha and Tanaka ${ }^{21)}$, the driftwood model after the trap cannot stay near the water surface by the downward flow around patch-type vegetation and moves downward. When several driftwoods are trapped, a debris dam is formed near the bed and water overtops the debris dam. A similar phenomenon with the experiment could occur at the site after the debris was trapped. The four cases of simulation by changing with/without vegetation and with/without trapping show around $0.5 \mathrm{~m}$ differences among the cases. From Fig.11(a), the simulation shows satisfactory agreement for discussing the effect of vegetation washout and trapping.

\section{(3) Reproduction of the washout situation of per- ennial grasses and trees}

Figure 12(a) and (b) show the actual and simulated washout situation of the target perennial grasses,

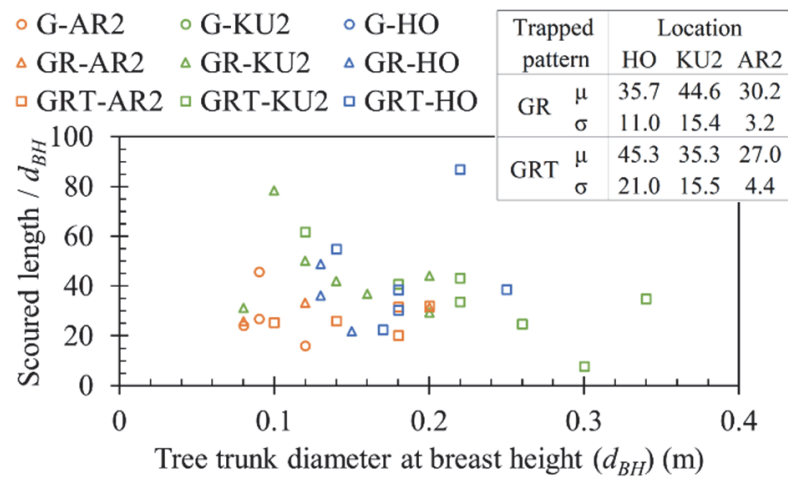

Fig.10 Relationship between $d_{B H}$ and non-dimensionalized scoured length.
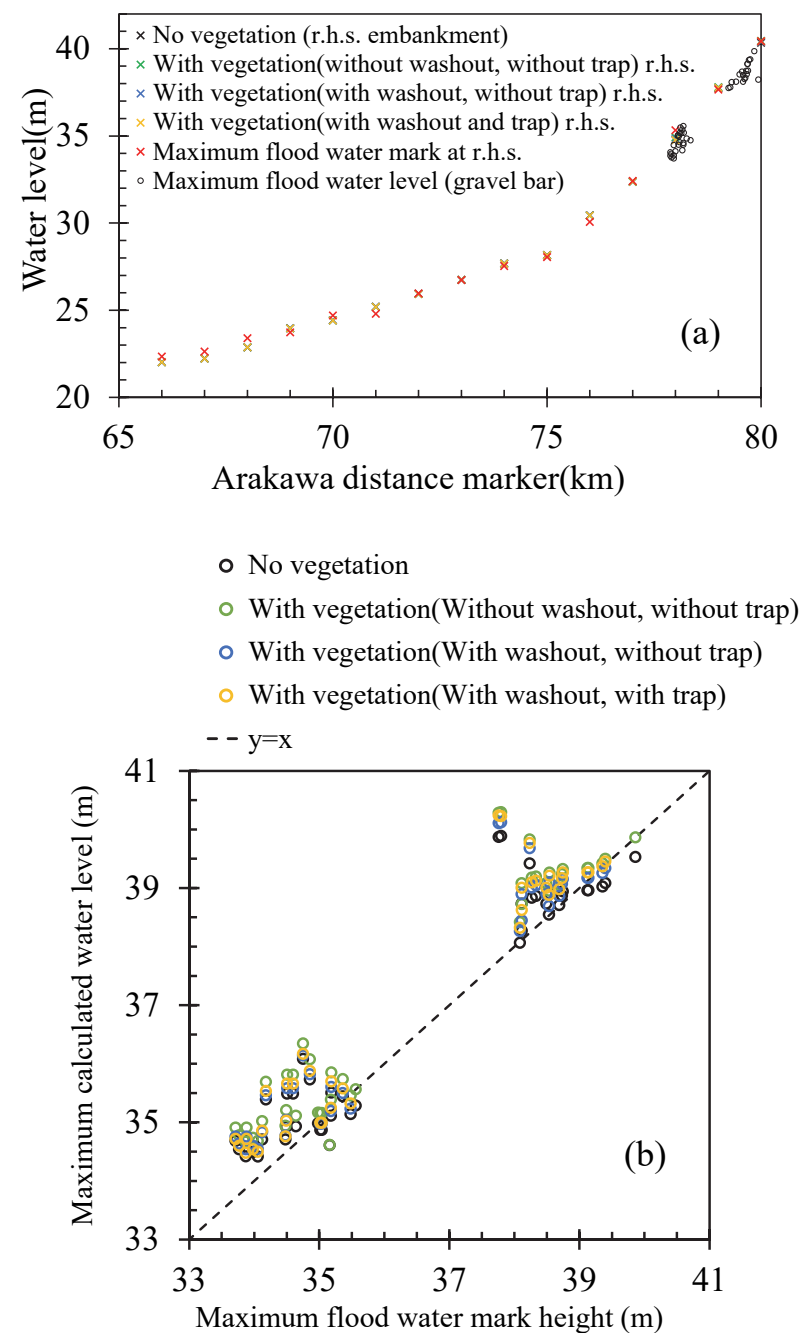

Fig.11 Validation of the model comparing maximum calculated water level with; (a) right hand side (r.h.s.) maximum water marks at embankment and part of the marks on gravel bars, (b) maximum marks on gravel bars.

respectively.

The hatched areas A and B show 'all grasses are washed out' and 'most of the grasses have remained,' respectively. The area unhatched in Fig. 12(a) cannot be clearly distinguished by UAV photos. The location where the grasses are washed out is 'the location around low channel' or 'on the low elevation gravel bars.' At the r.h.s. of the AR2, Phragmites japonica 


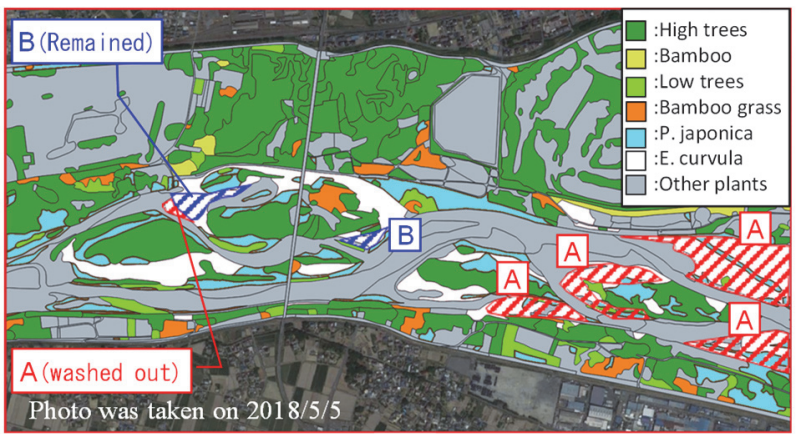

(a)

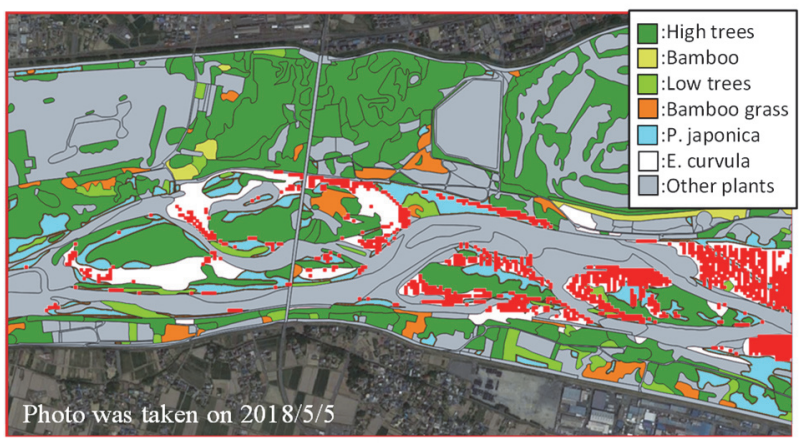

(b)

Fig.12 Washout situation of representative grasses, (a) field investigation, (b) analyzed result (red dot represents the washout of the grasses), Modified from the Google Earth. Upper side of this figure is the north.

is washed out by the bankside erosion. Although the bankside erosion is not included in the simulation, large shear stress acts near the bank and the plant's washout is well reproduced. The trapping does not affect the washout of grasses because the washout area is mainly lower than the trapped area of the gravel bars.

Figure 13 compares the washout condition of trees in simulation with the field. Figure 13(a) is the case for modeling with washout trees and without trapping debris. Figure 13(b) is the case for modeling with washout trees and with trapping debris. Figure 13(b) also shows the actual location of tree washout as hatched C. When trapping occurs (Fig.13(b)), the sheltering region is generated because of a larger resistance around the forest. Then, tree breaking judged by MOI and washout judged by WOI do not occur in the forest. Especially, almost all the trees are simulated 'washout' inside the forest in AR1 and AR2 in case of no trapping (Fig.13(a)). Figure 13(b) shows no destruction inside the forest. Hence, including the trapping phenomenon can better reproduce the actual situation.

\section{(4) Change in the storage in river at the destruc- tive flood event}

Figure 14(a) and (b) show the difference in velocities for with/without vegetation washout and trapping debris, respectively. Both subtract the values of 'the case without' from 'the case with.' Figure 14(a)

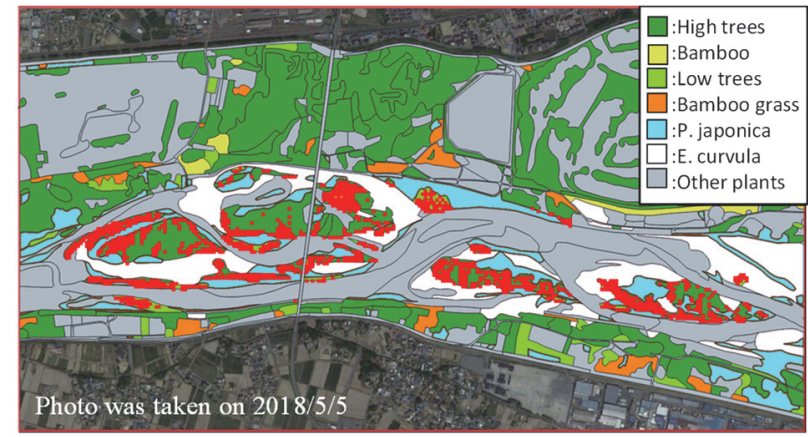

(a)

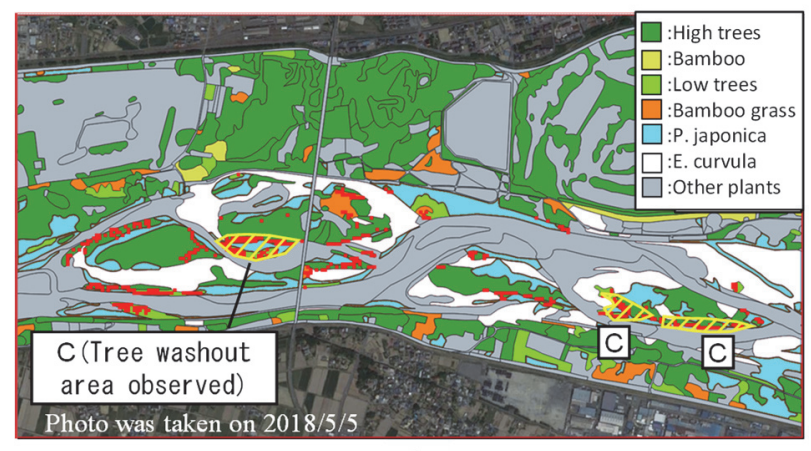

(b)

Fig.13 Washout situation (red dits) of representative trees, (a) simulated results without trap, (b) comparison of simulated results which includes trapping phenomena with field investigation, Modified from the Google Earth. Upper side of this figure is the north.

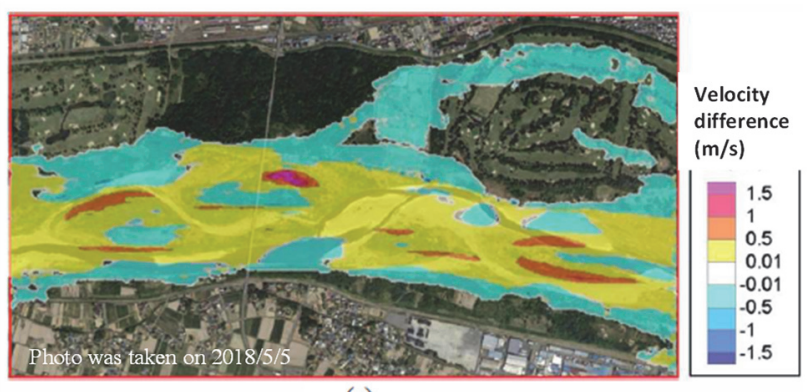

(a)

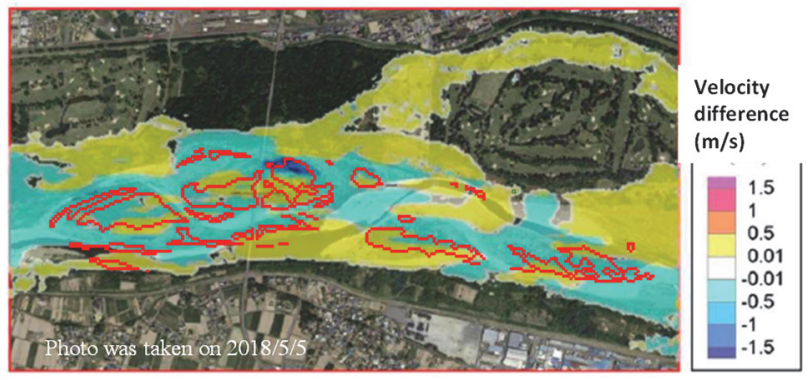

(b)

Fig.14 Contour map of the velocity difference. (a) (with washout) - (without washout), (b) (with trap) - (without trap). Red line of (b) represents the remained trees after simulation. Modified from the Google Earth. Upper side of this figure is the north.

shows a trend where the velocity increases by the washout except for the area where the vegetation remains. Figure 14(b) shows a trend where velocity decreases at the upstream and downstream region of the trapped area, but velocity on the contrary 
increases at the side of the trapped forest. As the site investigated has a very wide river channel and embankment is far from the gravel bars, the repelling current effect on the embankment can be assumed low at this site. However, the influence of trapping near the embankment is pointed out at smaller-width rivers ${ }^{18)}$. Ti clarify the influences of trapping on the safety of river embankment, the relationship among the vegetation patch size, river width, and the distance from the patch and the embankment should be investigated with the effect of trapping, because the trapping greatly changes the local flow structures.

Figure 15(a) shows the discharge hydrograph from 10:00 on $12^{\text {th }}$ to $18: 00$ on $13^{\text {th }}$ October. As the difference is very small with this scale, the time-series around the peak and after the peak is shown in Figs.15(b) and 15(c), respectively. The location where the discharge hydrograph is calculated is the most downstream part in the fine grid region in Fig.6(a). Comparing the four cases, the difference starts when the flood water inundates on the gravel bars and the differences are caused by the difference in how the model includes the vegetation washout and trapping phenomena. Before the flood peak, the case with vegetation and without washout shows the smallest discharge (Fig.15(b)). In addition, the peak time is slightly delayed in this case. The trapping case decreases the peak around $10\left(\mathrm{~m}^{3} / \mathrm{s}\right)$ compared with washout but no trapping case. After the peak (especially after $30 \mathrm{~h}$ ), the opposite trend happens. Thus, the existing vegetation and trapping phenomenon have a water storage function.

Figure 16 shows the difference in the cumulative discharge by subtracting the data of the case without washout from that of the case with washout and trap. The difference in Fig.15 shows the trend more clearly. The difference becomes larger after around $10 \mathrm{~h}$ and increases till $18 \mathrm{~h}$, and the difference becomes smaller (decreasing trend) after $30 \mathrm{~h}$. During 10-18 hrs, storage in river channel increases, and the stored water gradually runs off downstream.

From Fig.11, the washout and trap phenomena occurred on the gravel bar can be assumed that they did not affect the maximum water level at the embankment. The local water depths increased in front of the debris dam and inside the forest, and decreased around the forest. Although above local differences in water level existed around the forest, as a whole, the trapping phenomenon acted to store water (Fig.15) in this river reach. Although the forestation effect on the increase of flooding risk at this site is low because of the wide channel in comparison with the gravel bars width, and because there are no low bridges that can pile up the driftwood, the function to store flood water and change the discharge hydrograph should be considered from the point of view of
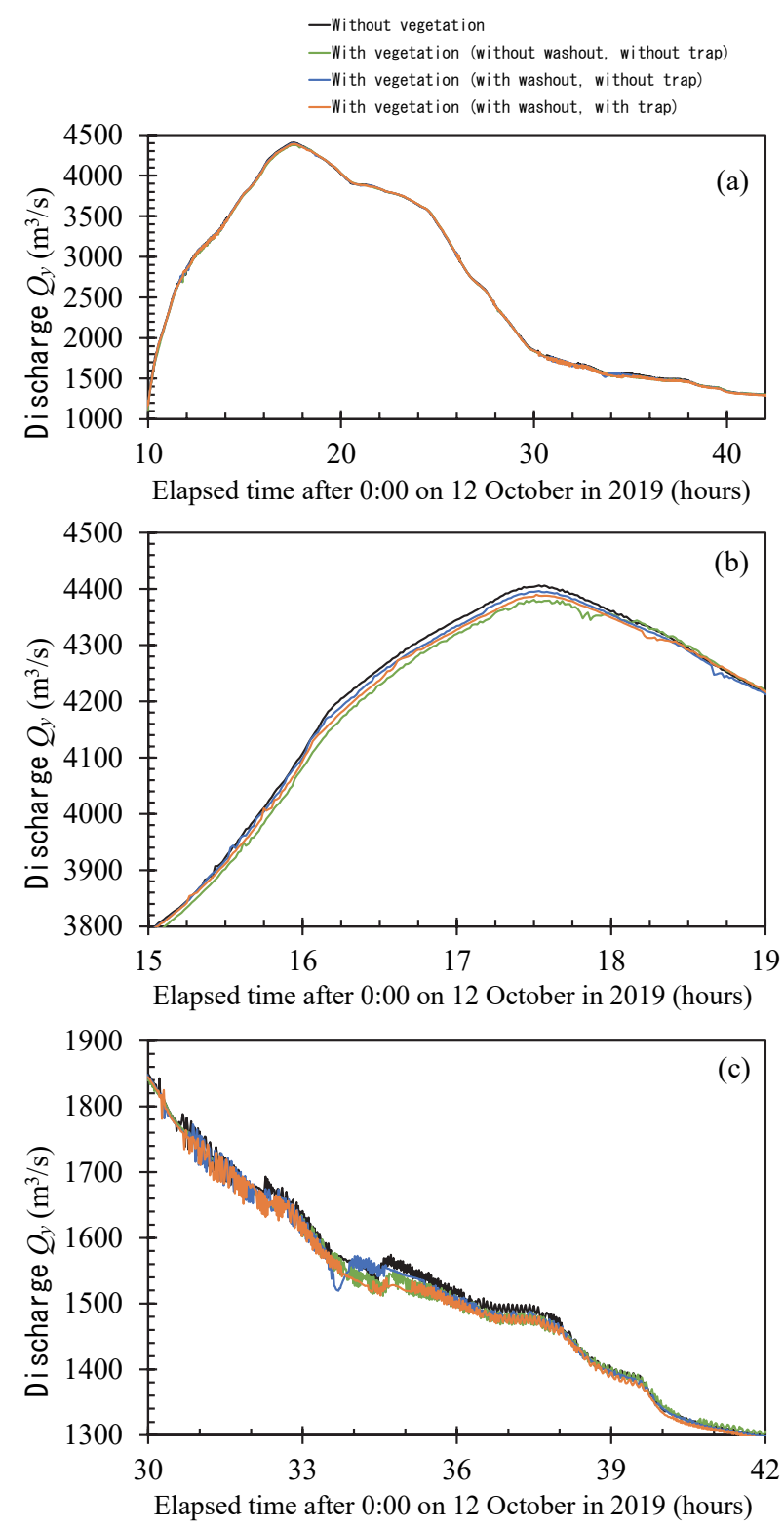

Fig.15 Discharge hydrograph at the downstream location of fine grid area (Fig.6), (a) whole flood event, (b) around a peak, (c) after the peak.

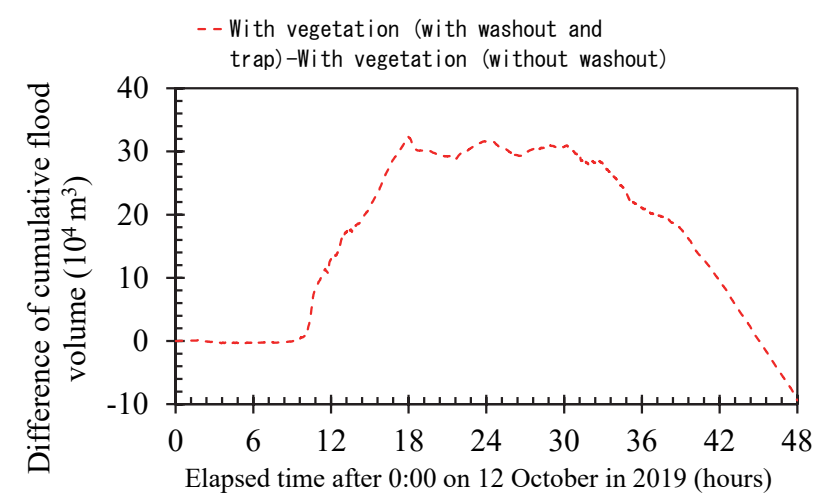

Fig.16 Difference of cumulative discharge of "with washout and trap' and 'without trap.'

upstream and downstream flood risk balance. The function to change the discharge hydrograph can increase when the gravel bar width corresponding to 
the river width is large. Thus, from that point, forest in the river should also be managed.

\section{CONCLUSION}

The conclusions derived are as follows:

\section{(1) Characteristics of trapped driftwoods and grasses}

The material of the trapped debris clump (TDC) can be classified as G (grasses), GR (grasses, roots, and branches), and GRT (tree trunks and GR material). Most of the TDC in front of or at the fringe of the forest is GRT; by the filtering, the TDC inside the forest is G or GR. The width of TDC is related to the trapped location and the material.

\section{(2) Change in velocities around the trapped loca- tion and the levee}

River flow simulation including the washout of vegetation and the trap shows that the velocities on the gravel bar at the Arakawa River increases where washout occurs, or decreases where there is trapping. Although the flow is accelerated around the forest that traps the debris, the velocity decreases on an average and water storage occurs in the reach. The storage occurs locally around the vegetation and does not affect the maximum water level at the embankment.

\section{(3) Change in the model accuracy by including trapping phenomenon}

By including the debris trapping phenomenon, tree washout situation in the sheltering region behind the debris dam can be improved.

Although the proposed model can better replicate the vegetation washout condition by the shear stress index (WOI) and the change in roughness and drag force, it is better to include the morphological change effects in the future simulations to further improve the modeling accuracy of large destructive flood events.

ACKNOWLEDGMENT: This study is partly funded by KAKENHI (Typhoon Hagibis). Data were provided by Ministry of Land, Infrastructure, Transport and Tourism, Japan.

\section{REFERENCES}

1) Ministry of Land, Infrastructure, Transport and Tourism, Japan, Damaged situation by the Typhoon Hagibis in 2019: List of levee-breach locations summarized at April $10^{\text {th }}$ in 2020 (in Japanese), (https://www.mlit.go.jp/common/00131 3204.pdf), 2020.

2) Ministry of Land, Infrastructure, Transport and Tourism, Japan, The $1^{\text {st }}$ Expert meeting handout on the the river improvement plan for the Arakawa River: Inspection on the river improvement plan for the Arakawa River (in Japanese), 2020. (https://www.ktr.mlit.go.jp/river/shihon/river_shihon 00000378.html)

3) Matsuura, S. and Matsui, H.: People and area struggling with floods: Chujo Levee around Tonegawa River and Heavy flooding event in Meiji 43, Sakitama Press, 2014 (in Japanese).

4) Otsuka, K.: Floods and the river improvement in the middle reach of the Arakawa River, Yoshimi and Kawajima District, in the Modern Period, Report after longterm training in Board of Education in Saitama, 1985 (in Japanese).

5) Tanaka, N., Yagisawa, J. and Fukuoka, S.: Difference in wash-out condition of trees due to floods with respect to the vegetated location on gravel-bed bars, Annual Journal of Hydraulic Engineering, Vol.53, pp.631-636, 2009 (in Japanese with English abstract).

6) Tanaka, N., Igarashi, Y. and Fushimi K.: Effects of existing second embankments constructed in Edo era on sensible flooding risk in the middle reach of the Arakawa River, Journal of Japan Society of Civil Engineers, Ser. B1 (Hydraulic Engineering), Vol.74, No.4, pp.I_1393-I_1398, 2018 (in Japanese with English abstract).

7) Watanabe, Y., Ichikawa, Y. and Ide, Y.: Critical conditions for trees lodging in flood plain during flood, Annual Journal of Hydraulic Engineering, Vol.40, pp.169-174, 1996 (in Japanese with English abstract).

8) Sunada, K., Kono, I. and Tanaka, S.: Basic study on the prediction of extent of tree destruction in river channel by flood, Annual Journal of Hydraulic Engineering, Vol.46, pp.947952, 2002 (in Japanese with English abstract).

9) Fujita, K., Lee, S., Watanabe, S., Tsukahara, T., Yamamoto, K. and Mochizuki, T.: Mechanism and simulation of the expansion and extinction of stable vegetation areas in a gravelbed alluvial fan river, Journal of Japan Society of Civil Engineers, Ser. B1 (Hydraulic Engineering), No.747/II-65, pp.41-60, 2003 (in Japanese with English abstract).

10) Shimizu, Y.: Increase of vegetation in gravel-bed rivers from land morphology, bed material and flood disturbance (in Japanese), The $44^{\text {th }}$ Summer Workshop in hydraulics, JSCE Hydraulic Eng. Committee, 2008.

11) Tanaka, N., Yagisawa, J. and Otsuka, S.: Method for evaluating the forestation in river considering the characteristics of flood decline and geomorphology of gravel bars on the deposition of fine sand, Journal of Japan Society of Civil Engineers, Ser. B1 (Hydraulic Engineering), Vol.70, No.3, pp.60-70, 2014 (in Japanese with English abstract).

12) Tanaka, N., Takenaka, H., Yagisawa, J. and Morinaga, T.: Estimation of drag coefficient of a real tree considering the vertical stand structure of trunk, branches, and leaves, Intl. J. River Basin Management, Vol. 9, Nos. 3-4, pp. 221-230, 2011.

13) Ashida, K. and Michiue, M.: Study on hydraulic resistance and bed-load transport rate in alluvial streams, J. of JSCE, No. 206, pp.59-69, 1972.

14) Tanaka, N. and Yagisawa, J.: Effects of tree characteristics and substrate condition on critical breaking moment of trees due to heavy flooding, Landscape Ecol. Eng., Vol.5, pp.5970, 2009.

15) Tsujimoto, T., Murakami, Y. and Yasui, T.: Growth of vegetation in fluvial-fan segment due to decrease of destruction of vegetation by floods, Annual Journal of Hydraulic Engineering, Vol.45, pp.1105-1110, 2001 (in Japanese with English abstract).

16) Egger, E., Benjankar, R., Davis, L. and Jorde, K.: Simulated effects of dam operation and water diversion on riparian vegetation of the lower Bois River Idaho, USA, 32nd IAHR Congress (CD-ROM), 2007. 
17) Yagisawa, J. and Tanaka, N.: Wash-out conditions of plants growing on islands by floods, Research Rep. of Dept. of Civil and Env. Eng., Saitama Univ., Vol.37, pp. 9-20, 2010.

18) Fushimi K., Tanaka, N. and Igarashi, Y.: The change in the sensible flooding risk and escape timing in the Kawajima Town in middle reach of the Arakawa River Basin in relation to the rainfall patterns and breaching conditions, Journal of Japan Society of Civil Engineers, Ser. B1 (Hydraulic Engineering), Vol.74, No.5, pp.I_1291-I_1296, 2018 (in Japanese with English abstract).

19) Igarashi, Y., Tanaka, N., Suenaga, H. and Matayoshi, K.: Influence of vegetation in tributaries of the Arakawa middle basin on flood flow and evaluation of ecological function,
Advances in River Engineering, JSCE, Vol.26, pp. 95-100, 2020 (in Japanese).

20) Ministry of Land, Infrastructure, Transport and Tourism, Japan, Runoff model of the Arakawa River (http://www.ktr. mlit.go.jp/ktr_content/content/000638163.pdf), 2015 (in Japanese).

21) Pasha, G. A. and Tanaka, N.: Effectiveness of finite length inland forest in trapping tsunami-borne wood debris, $J$. of Earthquake and Tsunami, Vol. 10, No. 2, 1650008 (26 pages), 2016.

(Received April 22, 2021) (Accepted August 24, 2021) 